\title{
Growth hormone treatment in Turner syndrome accelerates growth and skeletal maturation
}

\author{
C. Rongen-Westerlaken ${ }^{1}$, J.M.Wit ${ }^{1}$, S.M.P. F. De Muinck Keizer-Schrama ${ }^{2}$, B.J. Otten ${ }^{3}$, W. Oostdijk ${ }^{4}$, \\ H.A. Delemarre-van der Waal ${ }^{5}$, M.H.Gons ${ }^{6}$, A.Bot ${ }^{7}$, and J.L.Van den Brande ${ }^{1}$ \\ (Dutch Growth Hormone Working group) \\ ${ }^{1}$ Department of Paediatrics, University of Utrecht, Utrecht, The Netherlands \\ ${ }^{2}$ Department of Paediatrics, University of Rotterdam, Rotterdam, The Netherlands \\ ${ }^{3}$ Department of Paediatrics, University of Nijmegen, The Netherlands \\ ${ }^{4}$ Department of Paediatrics, University of Leiden, Leiden, The Netherlands \\ ${ }^{5}$ Department of Paediatrics, Amsterdam Free University, Amsterdam, The Netherlands \\ ${ }^{6}$ Department of Paediatrics, University of Amsterdam, Amsterdam, The Netherlands \\ ${ }^{7}$ Department of Endocrinology, Growth and Reproduction of the Erasmus University, Rotterdam, The Netherlands
}

Received July 8, 1991 / Accepted after revision November 18, 1991

\begin{abstract}
Sixteen girls with Turner syndrome (TS) were treated for 4 years with biosynthetic growth hormone (GH). The dosage was $4 \mathrm{IU} / \mathrm{m}^{2}$ body surface s.c. per day over the first 3 years. In the 4 th year the dosage was increased to $6 \mathrm{IU} / \mathrm{m}^{2}$ per day in the 6 girls with a poor height increment and in 1 girl oxandrolone was added. Ethinyl oestradiol was added after the age of 13 . Mean (SD) growth velocities were 3.4 (0.9), 7.2 (1.7), 5.3 (1.3), $4.3(2.0)$ and $3.6(1.5) \mathrm{cm} /$ year before and in the $1 \mathrm{st}$, 2 nd, 3 rd and 4 th year of treatment. Skeletal maturation advanced faster than usual in Turner patients especially in the younger children. Although the mean height prediction increased by $5.6 \mathrm{~cm}$ and 11 of the 16 girls have now exceeded their predicted height, the height of the 4 girls who stopped GH treatment exceeded the predicted adult height by only 0 to $3.4 \mathrm{~cm}$.
\end{abstract}

Key words: Turner syndrome - Growth hormone - Growth

\section{Introduction}

Turner syndrome (TS) is a genetic disorder which is associated with short stature $[5,7,13,14]$. The reason for this growth failure is unknown and cannot be explained by growth hormone $(\mathrm{GH})$ deficiency $[3,6]$. In spite of this, biosynthetic $\mathrm{GH}$ has been advocated for patients with TS. Preliminary results of GH treatment in girls with TS

Offprint requests to: $\mathrm{C}$. Rongen-Westerlaken, University Hospital Nijmegen, Department of Pediatrics, P.O.Box 9101, $6500 \mathrm{HB}$ Nijmegen, The Netherlands

Abbreviations: $\mathrm{GH}=$ growth hormone; $\mathrm{GP}=$ Greulich and Pyle; TS $=$ Turner syndrome; TW-RUS $=$ Bone age according to the method of Tanner and Whitehouse (Radius, ulna and short bones) have revealed an acceleration of statural growth, but so far few data are available about epiphyseal maturation during $\mathrm{GH}$ treatment.

In two earlier papers $[9,10]$ we have reported the response to biosynthetic methionyl human GH administered subcutaneously once daily at a dosage of $4 \mathrm{IU} / \mathrm{m}^{2}$ body surface for a period of 1 and 2 years. We now present the 4-year results.

\section{Patients and methods}

\section{Patients and therapy}

Sixteen girls with TS entered the study. During the first 2 years the children received methionyl GH (Somatonorm, Kabi, Stockholm, Sweden) and in the $3 \mathrm{rd}$ and 4 th year they received recombinant authentic GH (Genotropin, Kabi, Stockholm, Sweden) in a daily dosage of $4 \mathrm{IU} / \mathrm{m}^{2}$ body surface subcutaneously (equivalent to 0.9 (0.26) IU/kg body weight per week). If the height increment over the preceding 6 months was below $1 \mathrm{~cm}$, the $\mathrm{GH}$ dosage was increased to $6 \mathrm{IU} / \mathrm{m}^{2}$ in six patients after 36 to 45 months of treatment. GH treatment was discontinued if height increment was less than $0.5 \mathrm{~cm}$ over the previous 6 months. Low dose ethinyl oestradiol $(0.1 \mu \mathrm{g} / \mathrm{kg}$ od, orally) was added in patients over the age of 13 . In this report the results for the 13 patients who completed the 4-year period are given. The remaining three cases and also the two cases who discontinued treatment after 4-years of GH treatment are described individually.

\section{Growth analysis}

Height was expressed in SDS using the Dutch cross-sectional references [8] (SDS $(X X))$ and the references for Turner girls compiled by Lyon et al. (SDS(XO)) [5]. The growth velocity was expressed as $\mathrm{cm} /$ year and for comparison the velocity curves of girls with TS prepared by Ranke et al. were used [7].

The skeletal maturation (Tanner and Whitehouse 20-bones (TW-20), Tanner and Whitehouse-RUS (TW-RUS) [15] and Greulich and Pyle (GP) [1] was assessed by an experienced investigator. The advancement in bone age (TW-RUS) was compared with 
Turner references [7]. For the present report we also analysed the roentgenographs serially with the GP atlas without using the scores of the carpal bones. This method was chosen because it has been shown that the maturation of carpal bones is not an important determinant in adult height prediction [16].

The relationship of the height increment to skeletal maturation was assessed by computing the height SDS for bone age: the "index of potential height (IPH)" described by Lenko [4] and Joss [2] by using mean (SD) height values for bone age (TW-RUS) in patients with Turner syndrome.

The prediction of adult height was calculated on the basis of the tables of Bayley-Pinneau and on the basis of extrapolating initial height SDS (projected adult height) [11].

For more details about patients and methods the reader is referred to the previous reports $[9,10]$.

\section{Statistical analysis}

Results are expressed as mean (SD) except if indicated otherwise. The paired Student $t$-test and the Wilcoxon matched paired signed rank test were used for the analysis of within-group changes. The correlations between various parameters were calculated by the Spearman correlation test.

\section{Results}

\section{Growth}

The results of the 13 patients who completed the 4-year treatment period are given in Table 1. Height expressed as SDS (XO) increased significantly during treatment. We observed a significant negative correlation $(P=$ $0.001)$ between the increment in height $(\mathrm{cm})$ after 4 years of treatment and age. The increment in height expressed as SDS for Turner references was not correlated with age.

Growth velocities during the 1st, 2nd and 3rd year were significantly higher than before treatment. The growth velocity in the 4th year was not significantly different from that prior to treatment. In three of the six patients the increase in $\mathrm{GH}$ dosage led to a growth velocity increment of $0.9,1.8$ and $1.8 \mathrm{~cm}$. However, this increase was of short duration (approximately 6 months). In the other three patients the growth velocity further decreased.

Four patients discontinued treatment and 1 patient changed treatment because of a poor growth velocity of 0.6 to $1.3 \mathrm{~cm} /$ year. The results are summarized in Table 2 and the individual growth curves are given in Fig. 1 .

\section{Skeletal maturation and predicted adult height}

Skeletal maturation (TW-RUS) during the treatment period was $4.2(1.3)$ years, significantly $(P=0.001)$ higher than expected in untreated patients with TS during the same period (3.1 (0.7)) [7]. In Fig. 2a and b skeletal maturation in relation to age is visualized, before and after 3 years of treatment. Three years was taken because during the 4th year several children discontinued treatment. The increment in the bone age (TW-RUS) was significantly negatively correlated with chronological age $(P=$ 0.01 ). To exclude the effect of oestrogens on skeletal maturation we evaluated the data of the 6 patients who received only GH during 3 years. The bone age (TWRUS) in these six patients increased by $3.8(0.7)$ years, significantly more $(P<0.05)$ than the expected change $(2.8(0.2))$ over this period.

The mean (SD) index of potential height for Turner girls increased significantly during treatment; this corresponds to an improvement of approximately $5 \mathrm{~cm}$ in final height. The mean (SD) height prediction (GP) increased by $5.6(5.1) \mathrm{cm}$. Besides the four girls who stopped treatment, seven others exceeded their predicted adult height

Table 1. Selected growth variables over 4 years. Mean (SD)

\begin{tabular}{|c|c|c|c|c|c|}
\hline & 0 & 1 & 2 & 3 & 4 \\
\hline Height SDS (XX) & $-3.8(0.9)$ & $-3.4(1.1)^{* *}$ & $-3.3(1.2)^{* *}$ & $-3.3(1.3)$ & $-3.1(1.1)^{*}$ \\
\hline Height SDS (XO) & $0.1(0.8)$ & $0.7(0.8)^{* * * *}$ & $1.1(0.9)^{* * *}$ & $1.4(1.0)^{* * * *}$ & $1.5(1.1)^{* * *}$ \\
\hline $\mathrm{HV}$ (cm/year) & $3.4(1.0)$ & $7.6(1.6)^{* * *}$ & $5.6(1.1)^{* * *}$ & $4.8(1.9)^{*}$ & $3.6(1.5)$ \\
\hline BA (TW20) & $9.9(1.3)$ & $11.0(1.3)$ & $11.8(1.0)$ & $12.6(0.9)$ & $13.7(0.8)$ \\
\hline BA (TW-RUS) & $9.9(1.6)$ & $11.4(1.5)$ & $12.3(1.0)$ & $13.3(1.0)$ & $14.1(0.9)$ \\
\hline $\mathrm{BA}(\mathrm{GP})$ & $9.6(1.4)$ & $10.8(1.1)$ & $11.9(1.0)$ & $12.8(0.8)$ & $13.5(1.0)$ \\
\hline Height (SDS-BA) & $-0.1(0.6)$ & $0.3(0.7)^{*}$ & $0.6(0.7)^{* * *}$ & $0.8(1.0)^{* *}$ & $0.8(1.0)^{* *}$ \\
\hline $\mathrm{PAH}$ & $145.0(5.1)$ & $147.5(5.4)^{*}$ & $147.5(5.1)$ & $149.3(5.8)^{* *}$ & $150.6(5.8)^{* *}$ \\
\hline
\end{tabular}

Significantly different from the value before therapy

$* P<0.05$; ** $P<0.01 ; * * * P<0.001$

Table 2. Selected data of the 4 patients who disontinued treatment

\begin{tabular}{|c|c|c|c|c|c|c|c|c|}
\hline \multirow[t]{2}{*}{ Case } & \multicolumn{4}{|c|}{ Before treatment } & \multicolumn{4}{|c|}{ Stop treatment } \\
\hline & Age & BA & $\begin{array}{l}\text { Height } \\
\text { (SDS) }\end{array}$ & PAH & Age & $\mathrm{BA}$ & $\begin{array}{l}\text { Height } \\
(\mathrm{cm})\end{array}$ & $\begin{array}{l}\text { Height } \\
\text { (SDS) }\end{array}$ \\
\hline 1 & 13.1 & 11.5 & 0.2 & 142.1 & 16.6 & 15.0 & 142.5 & 0.4 \\
\hline 2 & 14.1 & 11.8 & 0.1 & 144.3 & 17.8 & 13.8 & 147.6 & 0.8 \\
\hline 3 & 9.6 & 8.3 & 1.2 & 152.4 & 13.6 & 13.6 & 152.6 & 2.3 \\
\hline 4 & 12.4 & 10.8 & 0.7 & 145.4 & 16.4 & 16.4 & 145.4 & 0.9 \\
\hline
\end{tabular}



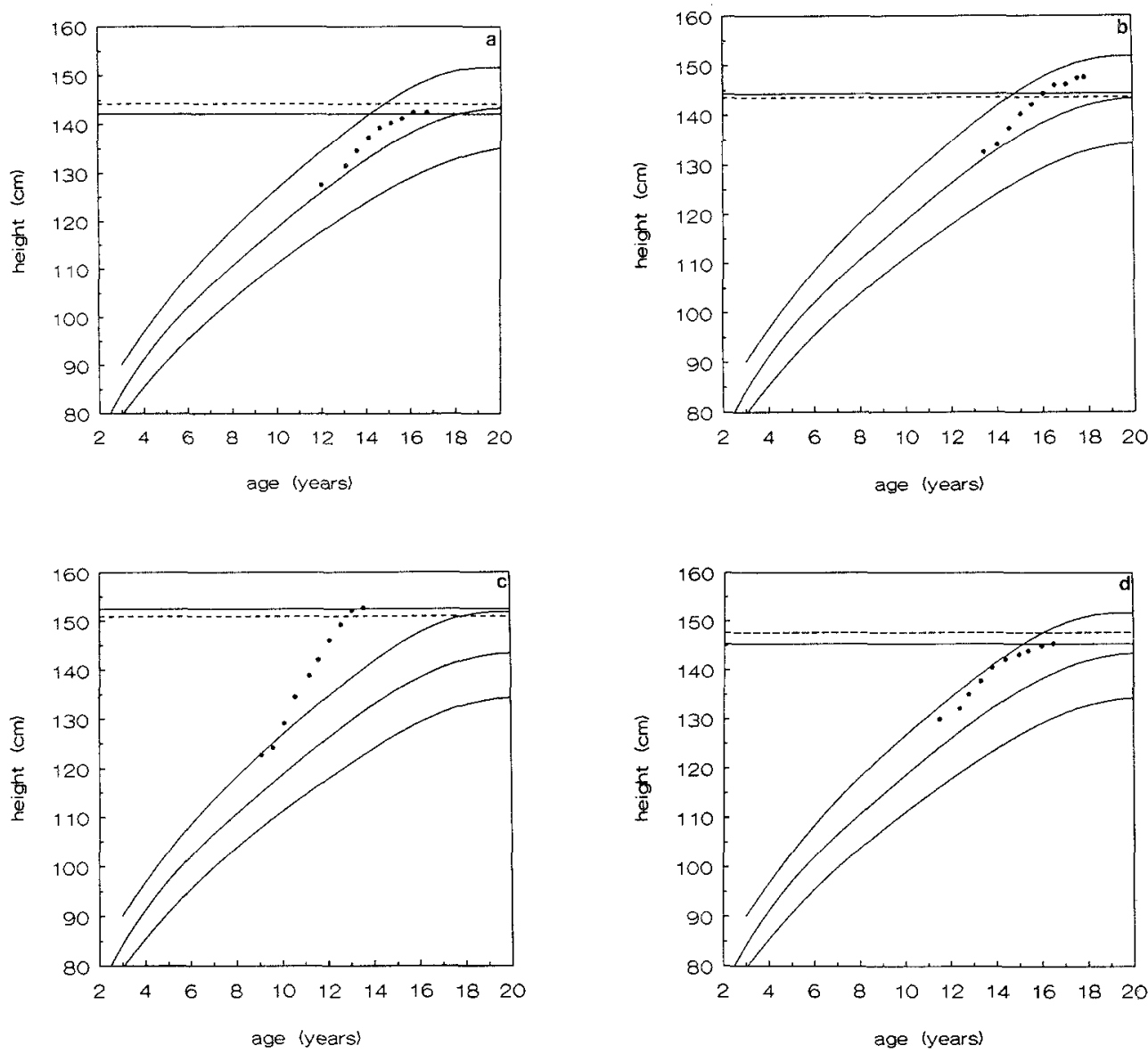

Fig. 1. Individual growth curves of the patients who discontinued treatment. (a-d representing cases 1-4) the interrupted line represents the adult height prediction based on the initial height SDS position and the continuous line represents the adult height prediction based on GP

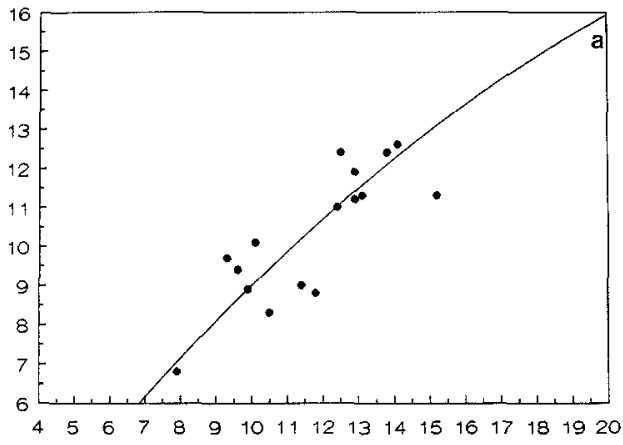

crronological age

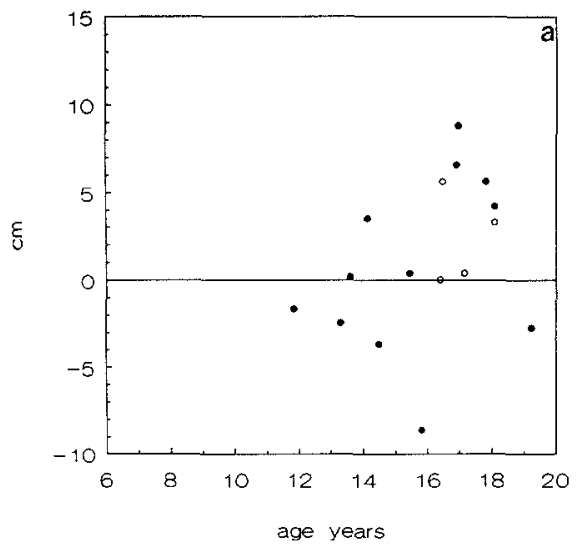

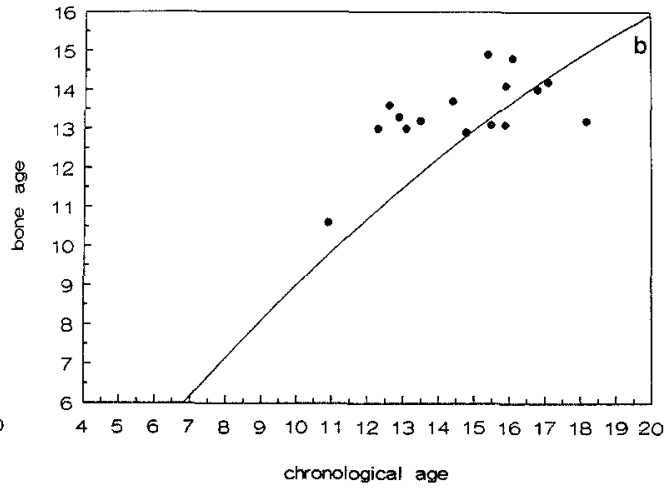

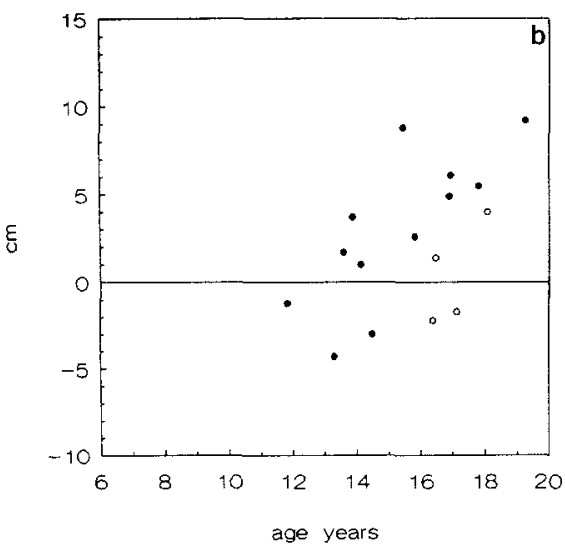

Fig. 2. Bone ages (TW-RUS) of all patients before (a) and after (b) 3 years of GH treatment plotted against the mean bone age for Turner girls in relation to age

Fig. 3. The difference between actual height after 4 years of treatment and initially predicted adult height (a) and projected adult height (b) in relation to age. The open circles visualize the patients who discontinued GH treatment and the closed circles the patients who are still on treatment 
by 0.03 to $8.8 \mathrm{~cm}$. Eleven girls exceeded their projected adult height by 1.0 to $9.2 \mathrm{~cm}$. The difference between statural height after 4 years of treatment and predicted or projected adult height in relation to age is shown in Figs. $3 a$ and $b$.

In the four patients who discontinued treatment bone age (GP) at discontinuation of treatment varied between 13.9 and 15 years and height was 0 to $3.4 \mathrm{~cm}$ above their initially predicted adult height and -2.2 to $+4 \mathrm{~cm}$ above their initially projected height. Growth velocity was poor $(1.1 \mathrm{~cm} /$ year) in one patient during $\mathrm{GH}$ treatment despite a bone age of only 12.3 years and it was decided to add oxandrolone to the medication. Hereafter the growth velocity increased to $5.1 \mathrm{~cm} /$ year.

\section{Intercurrent events}

No relevant events were reported.

\section{Discussion}

Our results confirm that treatment with $\mathrm{GH}$ promotes growth in children with TS. GH treatment resulted in a significant increase in height velocity and in height $\mathrm{Z}$ score (SDS) using Turner references. The increment in height SDS in our study after 3 years of treatment (1.4SD) is higher than found in the American study using GH alone in 3 injections/wk (0.9 SD) but less than in the children on $\mathrm{GH}$ and oxandrolone (2.1 SD) [11, 12]. In the 4th year there was little change in height SDS. There was a progressively diminishing effect of $\mathrm{GH}$ therapy on growth velocity.

To reach a higher final height, the increase in height must outweigh the increase in epiphyseal maturation. During treatment, skeletal maturation (TW-RUS) advanced 0.9 year faster than expected during the same period in untreated Turner patients [7]. The references for bone age (TW-RUS) [7] are based on girls with TS not treated with growth promoting substances, such as $\mathrm{GH}$ or oestrogens. The accelerated skeletal maturation in the six patients treated with $\mathrm{GH}$ alone strongly indicates that $\mathrm{GH}$ alone is able to accelerate skeletal maturation.

Before final height is actually reached, the effect of GH treatment on adult height can only be predicted. There are several methods for predicting adult height. Zachmann et al. [17] demonstrated that the GP method provided the most accurate height prediction in TS. However, only six children were investigated. The reliability of the "projected height" based on extrapolation of the height centiles was investigated by Lyon et al. [5], who found a slight underprediction averaging $-0.6 \mathrm{~cm}$. The results of the two prediction methods in our study before start of treatment were comparable: $144.1(5.4) \mathrm{cm}$ according to GP and 143.0 (4.7) by extrapolating height SDS. The prediction according to the method of GP increased by $5.6 \mathrm{~cm}$ during 4 years of treatment. After 4 years of treatment 11 of the 16 girls have exceeded their predicted adult height and also 11 of the 16 girls have exceeded their projected height. Furthermore there was an increase in mean height SDS for bone age. These data suggest that final height might be increased as a result of treatment with GH.

During this period four patients stopped GH treatment. The final heights exceeded the predicted heights by 0 to $3.4 \mathrm{~cm}$ and the projected heights by -2.2 to $4 \mathrm{~cm}$. These results are disappointing and are in contrast to the predicted increment of approximately $5 \mathrm{~cm}$ after 4 years of treatment in the whole group, although height at discontinuation of GH treatment is probably still somewhat lower than the future adult height. It is remarkable that one of the four patients stopped growing at a bone age at which growth should still be possible [7]. Another girl grew poorly on $\mathrm{GH}$ alone, although bone age was only 12.3 years. She responded very well after oxandrolone was added to the GH treatment. This illustrates that the growth promoting effect of oxandrolone is different in a qualitative sense from the effect of $\mathrm{GH}$ and it is well in line with the observation that $\mathrm{GH}$ and oxandrolone are additive in their effect [11]. It also indicates that on GH therapy growth may stop although the epiphyses in the hands have not yet fused, while further growth is possible with an anabolic steroid. Further research into this phenomenon is necessary because of the important clinical consequences.

In conclusion, in girls with TS GH increases height velocity but also accelerates skeletal maturation. The various prediction methods used for the 13 children who completed the treatment period of 4 years indicate that ultimate height will be approximately $5 \mathrm{~cm}$ higher than initially predicted adult height. However, there is considerable interindividual variation in the growth response to $\mathrm{GH}$ and the results in the four children who stopped GH treatment are disappointing. Therefore we feel that no firm conclusions can yet be drawn concerning the efficacy of GH therapy in terms of final height.

Acknowledgements. This study was made possible by the generous support of KabiVitrum (Sweden). Thanks are due to DrS.L.S. Drop for his role in initiating the study; to DrW.H. L. Hackeng for measuring anti-GH antibodies; to DrH. J.A. Wijnne for statistical advice; to Mrs M. van Zee and Mrs J. Copray for administrative support and manuscript preparation.

\section{References}

1. Greulich WW, Pyle SI (1959) Radiographic atlas of skeletal development of the hand and wrist. Stanford University Press, California

2. Joss EE (1988) Anabolic steroids in girls with Turner's Syndrome. Acta Paediatr Scand [Suppl] 343:38-42

3. Laczi F, Julesz J, Janaky T, Laszlo FA (1979) Growth hormone reserve capacity in Turner's syndrome. Horm Metab Res 11:664-666

4. Lenko HL (1979) Prediction of adult height with various methods in Finnish children. Acta Paediatr Scand 68:85-92

5. Lyon AJ, Preece MA, Grant MB (1985) Growth curve for girls with Turner syndrome. Arch Dis Child 60:932-935

6. Meadow SR, Boucher BJ, Mashitter K, King MNR, Stimmler L (1968) Growth hormone secretion in subjects with ovarian dysgenesis and Turner's Syndrome. Arch Dis Child 43:595597 
7. Ranke MB, Stubbe P, Majewski F, Bierich JR (1988) Spontaneous growth in Turner's syndrome. Acta Paediatr Scand [Suppl] 343:22-30

8. Roede MJ, Van Wieringen JC (1985) Growth diagrams 1980. Netherlands third nationwide survey. Tijdsch Soc Gezondheidszorg 63 [Suppl] : 1-34

9. Rongen-Westerlaken C, Fokker MH, Wit JM, et al (1990) Two year results of treatment with methionyl human growth hormone in girls with Turner syndrome. Acta Paed Scand 79: $658-663$

10. Rongen-Westerlaken C, Wit JM, Drop SLS, et al (1988) Methionyl human growth hormone in Turner's syndrome. Arch Dis Child 63: 1211-1217

11. Rosenfeld RG, Hintz RL, Johanson AJ, et al (1988) Three year results of a randomized prospective trial of methionyl human growth hormone and oxandrolone in Turner syndrome. J Pediatr 113:393-400

12. Rosenfeld RG, Hintz RL, Johanson AJ, et al (1986) Prospective, randomized trial of methionyl human growth hormone and/or oxandrolone in Turner syndrome. J Pediatr 109:936943

13. Snider ME, Solomon IL (1974) Ultimate height in chromosomal gonadal dysgenesis without androgen therapy. Am J Dis Child 127:4

14. Sybert VP (1984) Adult height in Turner syndrome with and without androgen therapy. J Pediatr 104:365-369

15. Tanner JM, Whitehouse RH, Takaishi M (1966) Standards from birth to maturity for height, weight, height velocity and weight velocity. British children, 1965 part II. Arch Dis Child $41: 613-694$

16. Tanner JM, Whitehouse RH, Cameron N, Marshall WA, Healy MJR, Goldstein H (1983) Assessment of skeletal maturity and prediciton of adult height (TW2-method). Academic Press, London

17. Zachmann M, Sobradillo B, Frank M, Frisch H, Prader A (1978) Bayley-Pinneau, Roche-Wainer-Thissen and Tanner height predictions in normal children and in patients with various pathologic conditions. J Pediatr 93:749-755 